\title{
An Assessment of the In Vitro Inhibition of Cytochrome P450 Enzymes, UDP-Glucuronosyltransferases, and Transporters by Phosphodiester- or Phosphorothioate-Linked Oligonucleotides ${ }^{\circledR}$
}

\author{
Faraz Kazmi, Phyllis Yerino, Chase McCoy, Andrew Parkinson, David B. Buckley, \\ and Brian W. Ogilvie
}

Sekisui XenoTech LLC, Kansas City, Kansas (F.K., P.Y., C.M., D.B.B., B.W.O.); Janssen Research \& Development LLC, Spring House, Pennsylvania (F.K.); XPD Consulting, Shawnee, Kansas (A.P.); and Roivant Sciences, Durham, North Carolina (D.B.B.)

Received March 27, 2018; accepted May 4, 2018

\section{ABSTRACT}

Oligonucleotides represent an expanding class of pharmacotherapeutics in development for various indications. Typically, oligonucleotides are developed with phosphorothioate linkages for the improvement of biologic stability; however, limited data are available on the potential of these molecules to cause drug-drug interactions (DDIs). In this study, four nontherapeutic oligonucleotides with either a phosphodiester or phosphorothioate linkage and partial sequences towards glutathione peroxidase or $\beta$-actin (PD-GP and PD-Ac or PT-GP and PT-Ac, respectively) were evaluated in vitro for their potential to inhibit cytochrome P450 (P450) enzymes and UGP-glucuronosyltransferases (UGTs) in both human liver microsomes (HLMs) and cryopreserved human hepatocytes (CHHs) and to inhibit select transporters in expression systems. PD-GP and PD-Ac had little to no inhibitory effect on any P450 or UGT enzymes in HLMs and CHHs, except for PD-Ac in HLMs for CYP2C19 $\left(\mathrm{IC}_{50}=29 \mu \mathrm{M}\right)$. Conversely, PT-GP and PT-Ac caused direct inhibition of almost all P450 and UGT enzymes, with CYP1A2 (IC 50 values of 0.8-4.2 $\mu \mathrm{M})$, CYP2C8 (IC ${ }_{50}$ values of 1.1-12 $\left.\mu \mathrm{M}\right)$, and UGT1A1 ( $\left(\mathrm{C}_{50}\right.$ values of 4.5-5.4 $\mu \mathrm{M}$ ) inhibited to the greatest extent. There was evidence of possible time-dependent inhibition (TDI) of P450 enzymes with PT-GP and PT-Ac for CYP2B6, CYP2C8, CYP2C19, CYP2C9, CYP2D6, and CYP3A4/5; however, this TDI was reversible. In contrast to HLMs, there was little to no direct P450 inhibition by any oligonucleotide in CHHs [except for PD-Ac with CYP2C19 $\left(\mathrm{IC}_{50}=36 \mu \mathrm{M}\right)$ and TDI by PT-GP with CYP2C8], demonstrating test system-dependent outcomes. Inhibition was observed for the organic anion uptake transporters, including organic anion-transporting polypeptide OATP1B1 and OATP1B3, organic anion transporters OAT1 and OAT3, and organic cation transporter OCT2 (IC 50 values of 12-29 $\mu \mathrm{M})$, but not OCT1 or the efflux transporters breast cancer resistance protein and P-glycoprotein by the phosphorothioate oligonucleotides.

\section{Introduction}

Oligonucleotide-based therapies represent an intriguing class of molecules being developed for a range of indications such as oncology, metabolic and genetic disorders, and infectious diseases (Aartsma-Rus,

Portions of this work were previously presented at the following meetings: Kazm F, Yerino P, Bixler E, McCoy C, and Buckley DB (2014) In vitro system-dependent inhibition of cytochrome P450 enzymes (CYP), UGP-glucuronosyltransferases (UGT) and transporters by oligonucleotides. 19th North American Regional International Society for the Study of Xenobiotics Meeting; 2014 Oct 19-23; San Francisco, CA; and Buckley D, Kazmi F, Yerino P, Ogilvie B, and Parkinson A (2009) Inhibition of cytochrome P450 (CYP) enzymes, CYP1A2 and CYP2C8, by oligonucleotides in human liver microsomes (HLM): a system-dependent outcome. 16th North American Regional International Society for the Study of Xenobiotics Meeting; 2009 Oct 18-22; Baltimore, MD.

https://doi.org/10.1124/dmd.118.081729.

S This article has supplemental material available at dmd.aspetjournals.org.
2016; Vasko et al., 2017; Rossor et al., 2018). Typically, these molecules are developed as small complementary base pair sequences to targets, known as antisense oligonucleotides (ASOs), allowing for specific knockdown of gene expression through Watson-Crick base pair binding with target mRNA followed by digestion by cellular nucleases. ASOs are often chemically modified to improve their pharmacokinetic properties such as phosphorothioate linkage in lieu of phosphodiester linkage to improve biologic stability (see Fig. 1), as well as other modifications to improve absorption and localization to the target (Yu et al., 2013; Chen et al., 2018). Generally, phosphorothioate-based ASOs have high plasma protein binding (>90\%) and rapidly distribute to tissues, while being subject to slow metabolism by cellular nucleases and eventual clearance primarily through urinary excretion of parent molecule and fragment ASO metabolites (Geary, 2009).

There have been limited studies on the potential for ASOs to act as perpetrators of pharmacokinetic drug-drug interactions (DDIs); however, these reports to date have shown no clinical DDIs with an array of

ABBREVIATIONS: ASO, antisense oligonucleotide; BCRP, breast cancer resistance protein; $\mathrm{CHH}$, cryopreserved human hepatocyte; DDI, drugdrug interaction; EMA, European Medicines Agency; FDA, U.S. Food and Drug Administration; HEK293, human embryonic kidney 293; HLM, human liver microsome; LC, liquid chromatography; MDCK-II, Madin-Darby canine kidney II; MDI, metabolism-dependent inhibition; MS/MS, tandem mass spectrometry; $\mathrm{m} / \mathrm{z}$, mass to charge ratio; OAT, organic anion transporter; OATP, organic anion-transporting polypeptide; OCT, organic cation transporter; P-gp, P-glycoprotein; P450, cytochrome P450; PD-Ac, phosphodiester-linked $\beta$-actin oligonucleotide; PD-GP, phosphodiester-linked glutathione peroxidase oligonucleotide; PT-Ac, phosphorothioate-linked $\beta$-actin oligonucleotide; PT-GP, phosphorothioate-linked glutathione peroxidase oligonucleotide; TDI, time-dependent inhibition; UGT, UDP-glucuronosyltransferase. 


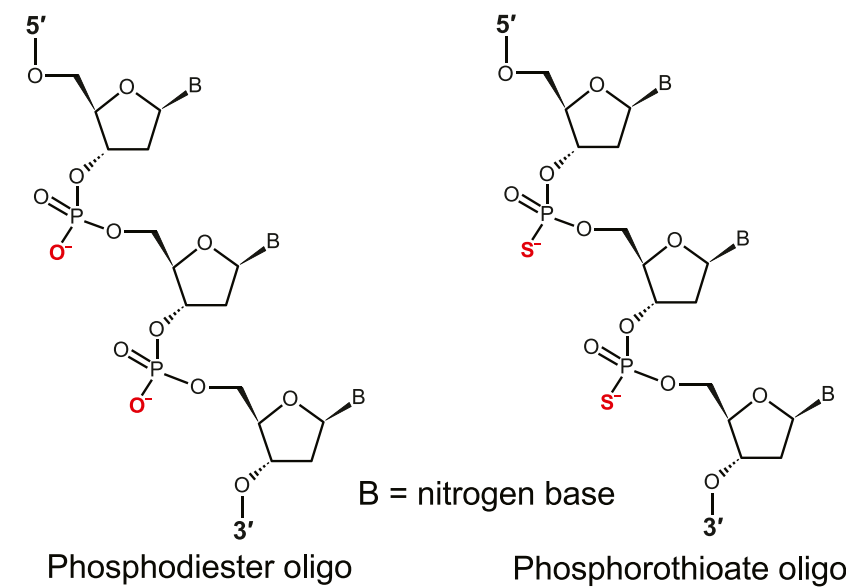

Fig. 1. General structures of oligonucleotides with phosphodiester or phosphorothioate linkages.

comedications cleared through a multitude of clearance pathways (Adjei et al., 2003; Villalona-Calero et al., 2004; Geary et al., 2006; Yu et al., 2009; Li et al., 2014). These include clinical interaction studies with warfarin (CYP2C9/3A4), simvastatin (CYP3A4), ezetimibe [multiple UDP-glucuronosyltransferases (UGTs)], rosiglitazone (CYP2C8/2C9), glipizide (CYP2C8/2C9), metformin (renal), cisplatin (renal), and gemcitabine (nucleoside kinases). Because ASOs are typically large $(>5 \mathrm{kDa})$ polyanionic molecules and given their non-cytochrome $\mathrm{P} 450$ (P450)-dependent metabolism and clearance, these molecules would not be expected to inhibit drug-metabolizing enzymes.

The recent 2017 U.S. Food and Drug Administration (FDA) draft industry guidance on "In Vitro Metabolism- and Transporter-Mediated Drug-Drug Interaction Studies" (https://www.fda.gov/downloads/ Drugs/GuidanceComplianceRegulatoryInformation/Guidances/ UCM581965.pdf) and the 2013 European Medicines Agency (EMA) "Guideline on the Investigation of Drug Interactions" (http://www.ema. europa.eu/docs/en_GB/document_library/Scientific_guideline/2012/ 07/WC500129606.pdf) provide guidelines on the specific types of in vitro studies necessary for new drug applications. Although neither the FDA nor EMA guidance documents have specific recommendations for ASO DDI evaluation, these molecules do fall under the scope of overall DDI testing despite their distinct physicochemical properties. As a result, studies such as inhibition of P450s and UGTs are required to be performed, including evaluations of time-dependent inhibition (TDI) for P450 enzymes. Typically, assessments of both TDI (preincubation of perpetrator compound) and metabolism-dependent inhibition (MDI; preincubation of compound with NADPH cofactor) are performed in the industry (Parkinson et al., 2011) because the former simply measures the effect of time on enzyme activity loss, whereas the latter assesses the impact of P450 metabolism on enzyme activity loss. The recent FDA and EMA recommendations also specify the use of subcellular fractions as well as cell-based systems, such as human liver microsomes (HLMs) and cryopreserved human hepatocytes (CHHs), for these studies. Furthermore, the evaluation of uptake and efflux transporter inhibition is recommended to be examined with appropriate test systems.

Upon performing the aforementioned in vitro studies in our laboratory with proprietary phosphorothioate ASO molecules, we unexpectedly observed P450 inhibition in HLMs. We hypothesized that this was not oligonucleotide sequence-specific inhibition, but rather an artifact due to the presence of the phosphorothioate linkage. This observation prompted us to perform this study with four generic nontherapeutic oligonucleotide sequences (partial sequences to glutathione peroxidase or $\beta$-actin) with and without phosphorothioate linkages as surrogates for therapeutic ASOs. In this study, glutathione peroxidase or $\beta$-actin partial sequence oligonucleotides with either a phosphorothioate or phosphodiester linkage (PT-GP and PT-Ac or PD-GP and PD-Ac, respectively) were evaluated as P450 and UGT inhibitors in both HLMs and CHHs. Furthermore, the potential for select transporter inhibition was also evaluated, specifically the uptake transporters such as organic aniontransporting polypeptides (OATPs), organic anion transporters (OATs), and organic cation transporters (OCTs) and the efflux transporters P-glycoprotein (P-gp) and breast cancer resistance protein (BCRP). Overall, this study reconciles in vitro DDI findings with the lack of interaction in clinical DDI reports for the oligonucleotide biomolecule class.

\section{Materials and Methods}

Oligonucleotides. Four approximately 20-base oligonucleotides with partial sequences toward glutathione peroxidase ( $5^{\prime}$-GCTCGTTCATCTGGGTGTAGT- $\left.3^{\prime}\right)$ and $\beta$-actin $\left(5^{\prime}\right.$-CCTCCTCTTTGTTCCCTTCT- $\left.3^{\prime}\right)$, each with either a phosphodiester or phosphorothioate linkage (generic structures shown in Fig. 1), were purchased from Integrated DNA Technologies (Coralville, IA).

Chemicals and Reagents. Chenodeoxycholic acid, digoxin, estradiol glucuronide, estrone sulfate, morphine, 1-naphthol, saccharic acid 1,4-lactone, oxazepam, $p$-aminohippuric acid, prazosin, propofol, testosterone, and trifluoperazine were purchased from Sigma-Aldrich (St. Louis, MO). Levomedetomidine was a gift from Orion Corporation (Espoo, Finland). $\left[{ }^{3} \mathrm{H}\right]$-Estradiol glucuronide and $\left[{ }^{3} \mathrm{H}\right]$-estrone sulfate were purchased from PerkinElmer (Waltham, MA). $\left[{ }^{14} \mathrm{C}\right]$-Metformin was purchased from Moravek Biochemicals (Brea, CA). $\left[{ }^{14} \mathrm{C}\right]$-Tetraethylammonium bromide and $\left[{ }^{3} \mathrm{H}\right]-p$-aminohippuric acid were purchased from American Radiolabeled Chemicals (St. Louis, MO). $d_{5}$-Testosterone $17-O$-glucuronide, $d_{5}$-oxazepam- $N$-glucuronide, and prochlorperazine glucuronide used as internal standards were prepared at Sekisui XenoTech LLC (Kansas City, KS). All other deuterated glucuronides were purchased from Toronto Research Chemicals (Toronto, ON, Canada). The sources of all other reagents were described previously (Parkinson et al., 2011; Kazmi et al., 2014, 2015b; Vermeer et al., 2016).

Test Systems. Pooled HLMs ( $n=200$, mixed gender) and pooled CHHs $(n=$ 100 , mixed gender) were prepared from nontransplantable livers and were characterized at Sekisui XenoTech LLC as described previously (Pearce et al., 1996; Parkinson et al., 2004). Human embryonic kidney 293 (HEK293) cells expressing transporter cells (HEK293 cells transfected with vectors containing human transporter cDNA for OATP1B1, OATP1B3, OAT1, OAT3, and OCT2) and control cells (HEK293 cells transfected with only vectors) were supplied by American Type Culture Collection (Manassas, VA) and transfected with the vector containing transporter cDNA by ADME \& Tox. Research Institute (Sekisui Medical Co. Ltd., Tokai, Japan). Madin-Darby canine kidney II (MDCK-II) cells transfected with BCRP were obtained from the Netherlands Cancer Institute (Amsterdam, Netherlands). Caco-2 cells were obtained from American Type Culture Collection.

In Vitro P450 and UGT Inhibition. The effects of oligonucleotides on P450 enzymes in HLMs were evaluated $(n=2)$ in $\mathrm{IC}_{50}$ experiments with and without a 30-minute preincubation step (in the presence and absence of NADPH) as described previously (Parkinson et al., 2011). For CHHs, incubations were conducted in duplicate $100 \mu 1$ mixtures containing 0.5 million cells $/ \mathrm{ml}$ in KrebsHenseleit buffer. Reactions were initiated by the addition of $\mathrm{CHHs}$ to the oligonucleotides and incubations were conducted at $37^{\circ} \mathrm{C}$ with $95 \%$ humidity and $5 \% \mathrm{CO}_{2} / 95 \%$ air for 0,30 , and 90 minutes, followed by the addition of a P450 marker substrate (or the broad specificity UGT substrate 4-methylumbelliferone) at a concentration approximately equal to its $K_{\mathrm{m}}$ (see Table 1). For incubations with sonicated hepatocytes (conducted with $10 \mu \mathrm{M}$ phosphorothioate oligonucleotides only), CHHs were disrupted with a probe sonicator (45 seconds at 40\%-60\% amplitude). Reactions were terminated after 10 minutes by the addition of $100 \mu 1$ acetonitrile containing the appropriate internal standard. Precipitated protein was removed by centrifugation ( 920 relative centrifugal force for 10 minutes at $10^{\circ} \mathrm{C}$ ) followed by liquid chromatography (LC)-tandem mass spectrometry (MS/MS) analysis. To assess whether P450 inhibition was caused by a low molecular weight contaminant, the oligonucleotides $(100 \mu \mathrm{M})$ were filtered through a 3-kDa microcentrifuge filter (Millipore, Billerica, MA) with the 
TABLE 1

Experimental conditions for measurement of P450 and UGT activity in HLMs and CHHs

\begin{tabular}{|c|c|c|c|c|c|c|c|c|c|}
\hline Enzyme & Marker Activity & $\begin{array}{c}\text { Substrate } \\
\text { Concentration }\end{array}$ & HLMs & $\mathrm{CHHs}$ & $\begin{array}{l}\text { Incubation Time } \\
\text { in HLMs }\end{array}$ & $\begin{array}{l}\text { Incubation } \\
\text { Time in CHHs }\end{array}$ & $\begin{array}{l}\text { Mass Transition } \\
\text { Monitored }\end{array}$ & $\begin{array}{l}\text { Ionization } \\
\text { Mode }\end{array}$ & Internal Standard \\
\hline & & $\mu M$ & $m g / m l$ & $\begin{array}{l}\text { million } \\
\text { cells } / m l\end{array}$ & $\min$ & $\min$ & $\mathrm{m} / \mathrm{z}$ & & \\
\hline CYP1A2 & Phenacetin $O$-deethylation & 40 & 0.1 & 0.5 & 5 & 10 & $150.0 / 107.0$ & Negative & $d_{4}$-Acetaminophen \\
\hline CYP2B6 & Bupropion hydroxylation & 50 & 0.1 & 0.5 & 5 & 10 & $256.1 / 238.0$ & Positive & $d_{6}$-Hydroxybupropion \\
\hline CYP2C8 & $\begin{array}{l}\text { Amodiaquine } \\
N \text {-dealkylation }\end{array}$ & $\begin{array}{l}1.5 \text { (7 for } \\
\text { CHHs) }\end{array}$ & 0.0125 & 0.5 & 5 & 10 & $328.2 / 283.1$ & Positive & $d_{5}-N$-Desethylamodiaquine \\
\hline CYP2C9 & Diclofenac 4 '-hydroxylation & 6 & 0.1 & 0.5 & 5 & 10 & $310.0 / 266.0$ & Negative & $d_{4}-4^{\prime}$-Hydroxydiclofenac \\
\hline CYP2C19 & $\begin{array}{l}S \text {-Mephenytoin } \\
\text { 4'-hydroxylation }\end{array}$ & 40 & 0.1 & 0.5 & 5 & 10 & $233.0 / 190.0$ & Negative & $d_{3}-4^{\prime}$-Hydroxymephenytoin \\
\hline CYP2D6 & $\begin{array}{l}\text { Dextromethorphan } \\
O \text {-demethylation }\end{array}$ & 7.5 & 0.1 & 0.5 & 5 & 10 & $258.0 / 157.1$ & Positive & $d_{3}$-Dextrorphan \\
\hline CYP3A4/5 & $\begin{array}{l}\text { Midazolam } \\
\text { 1'-hydroxylation }\end{array}$ & 4 & 0.1 & 0.5 & 5 & 10 & $342.0 / 324.0$ & Positive & $d_{4}-1^{\prime}$-Hydroxymidazolam \\
\hline UGT1A1 & $\begin{array}{l}\text { Estradiol } \\
\quad 3 \text { - } O \text {-glucuronidation }\end{array}$ & 9 & 0.1 & NA & 5 & NA & $4471 / 271.2$ & Negative & $\begin{array}{l}d_{5} \text {-Estradiol } \\
\text { 3-O-glucuronide }\end{array}$ \\
\hline UGT1A3 & $\begin{array}{l}\text { Chenodeoxycholic acid } \\
\text { 24- } O \text {-glucuronidation }\end{array}$ & 20 & 0.1 & NA & 10 & NA & $567.2 / 391.3$ & Negative & $\begin{array}{l}d_{5} \text {-Chenodeoxycholic acid } \\
24-O \text {-glucuronide }\end{array}$ \\
\hline UGT1A4 & $\begin{array}{l}\text { Trifluoperazine } \\
\text { glucuronidation }\end{array}$ & 12 & 0.1 & NA & 5 & NA & $584.0 / 408.0$ & Positive & $\begin{array}{l}\text { Prochlorperazine } \\
\text { glucuronide }\end{array}$ \\
\hline UGT1A6 & 1-Naphthol glucuronidation & 1 & 0.0125 & NA & 5 & NA & $319.1 / 143.1$ & Negative & $d_{7}$-Naphthol glucuronide \\
\hline UGT1A9 & Propofol glucuronidation & 20 & 0.1 & NA & 5 & NA & $353.2 / 177.1$ & Negative & $d_{17}$-Propofol glucuronide \\
\hline UGT2B7 & $\begin{array}{l}\text { Morphine } \\
\text { 3-O-glucuronidation }\end{array}$ & 400 & 0.1 & NA & 5 & NA & $462.0 / 286.0$ & Positive & $\begin{array}{l}d_{3} \text {-Morphine } \\
\text { 3-O-glucuronide }\end{array}$ \\
\hline UGT2B10 & $\begin{array}{l}\text { Levomedetomidine } \\
\text { glucuronidation }\end{array}$ & 7 & 0.1 & NA & 10 & NA & $377.0 / 201.0$ & Positive & $d_{4}-1^{\prime}$-Hydroxymidazolam \\
\hline UGT2B15 & $\begin{array}{l}S \text {-Oxazepam } \\
\text { glucuronidation }\end{array}$ & 50 & 0.1 & NA & 10 & NA & $463.0 / 286.4$ & Positive & $d_{5}-S$-Oxazepam glucuronide \\
\hline UGT2B17 & $\begin{array}{l}\text { Testosterone } \\
17-O \text {-glucuronidation }\end{array}$ & 5 & 0.1 & NA & 10 & NA & $465.1 / 289.0$ & Positive & $\begin{array}{l}d_{5} \text {-Testosterone } \\
17-O \text {-glucuronide }\end{array}$ \\
\hline UGT & $\begin{array}{l}\text { 4-Methylumbelliferone } \\
\text { glucuronidation }\end{array}$ & 70 & NA & 0.5 & NA & 10 & $352.9 / 177.1$ & Positive & $\begin{array}{l}d_{5}-7 \text {-Hydroxycoumarin } \\
\text { glucuronide }\end{array}$ \\
\hline
\end{tabular}

NA, not applicable.

filtrate $(n=2)$ assessed for P450 inhibition as described above. The reversibility of P450 TDI was evaluated as described previously (Ogilvie et al., 2011). Briefly, a 30 -minute preincubation of the phosphorothioate oligonucleotides $(10 \mu \mathrm{M})$ in HLMs was performed in duplicate, followed by ultracentrifugation of microsomes $\left(100,000 \mathrm{~g} ; 60\right.$ minutes, $\left.4^{\circ} \mathrm{C}\right)$. The supernatant fraction was discarded and the microsomal pellet was rinsed with potassium phosphate buffer $(50 \mathrm{mM}, \mathrm{pH} 7.4)$ followed by resuspension in $250 \mathrm{mM}$ sucrose. Protein concentration was determined by the Pierce BCA Protein Assay (Pierce, Rockford, IL) and residual P450 activity was assessed as described above. For UGT inhibition, assays were conducted as described previously (Kazmi et al., 2014, 2015b). Briefly, oligonucleotides were incubated in duplicate at $37^{\circ} \mathrm{C}$ in $150-\mu \mathrm{l}$ incubation mixtures containing pooled HLMs $(\leq 0.1 \mathrm{mg} / \mathrm{ml})$, Tris buffer $(100 \mathrm{mM}, \mathrm{pH} 7.7)$, $\mathrm{MgCl}_{2}(10 \mathrm{mM})$, EDTA (1 mM, pH 7.4), saccharic acid 1,4-lactone (0.1 mM), UDP-GlcUA $(10 \mathrm{mM})$, and a UGT marker substrate at a concentration approximately equal to its $K_{\mathrm{m}}$, at the final concentrations indicated in Table 1 as described previously. Reactions were initiated by the addition of UDP-GlcUA and terminated after 5 or 10 minutes by the addition of $175 \mu \mathrm{l}$ acetonitrile containing the appropriate internal standard. Precipitated protein was removed by centrifugation $\left(920\right.$ relative centrifugal force for 10 minutes at $10^{\circ} \mathrm{C}$ ) followed by LC-MS/MS analysis. The TDI for UGT enzymes was assessed with a single concentration of each oligonucleotide $(30 \mu \mathrm{M})$ with and without a 30-minute preincubation step (in the presence and absence of UDP-GlcUA) with the methodology described above.

In Vitro Uptake and Efflux Transporter Inhibition. To evaluate inhibition of uptake transporters, HEK293 cells expressing various human uptake transporters were plated in 24 -well plates and grown in an incubator $\left(37^{\circ} \mathrm{C}, 95 \%\right.$ relative humidity, $5 \% \mathrm{CO}_{2}$ ) for 2 days. On the day of the assay, cells were preincubated with oligonucleotides or solvent control $(n=2)$ for 15 minutes followed by a 2-minute incubation with a combination of probe substrate (a mixture of cold and radiolabeled compound) and oligonucleotide. The substrate concentrations were $50 \mathrm{nM}$ estradiol 17- $\beta$-glucuronide for the OATP1B1 and OATP1B3 assays (with approximately equimolar radiolabeled and cold substrate), $1 \mu \mathrm{M} p$-aminohippuric acid for OAT1 (1:4 ratio of radiolabeled to cold substrate), $50 \mathrm{nM}$ estrone 3-sulfate for OAT3 (approximately equimolar radiolabeled and cold substrate), and $5 \mu \mathrm{M}$ tetraethylammonium bromide and $10 \mu \mathrm{M}$ metformin for OCT1 and OCT2, respectively (all radiolabeled). Uptake assays were terminated by aspiration of the incubation media and the cells were then washed three times (first with a rinse with ice-cold phosphate-buffered saline containing $0.2 \%$ bovine serum albumin and then two rinses with ice-cold phosphate-buffered saline). For analysis, cells were extracted with $0.1 \mathrm{~N} \mathrm{NaOH}$ for scintillation counting on a Microbeta $^{2}$ instrument (PerkinElmer). Evaluation of efflux transporter inhibition was conducted in Caco-2 (multidrug resistance protein MDR1/P-gp) or MDCK-II cells (transfected with BCRP) plated on 24-well transwell plates. The bidirectional permeability of specific probe substrates $(10 \mu \mathrm{M}$ digoxin for Caco-2 cells and $1 \mu \mathrm{M}$ prazosin for MDCK-II cells) was measured $(n=2)$ in the presence of oligonucleotides. Oligonucleotides were added to both apical and basolateral sides for 120 minutes. After the incubation, samples were stopped with 50:50 (v/v) methanol/water and analyzed by LC-MS/MS.

Analytical Methods. Analysis of all P450 and UGT metabolites was conducted by LC-MS/MS as shown in Table 1 and described previously (Parkinson et al., 2011; Kazmi et al., 2014, 2015b). The analytical methods used to quantify digoxin and prazosin are described as follows. Analyst Instrument Control and Data Processing Software (version 1.6.1; AB Sciex, Framingham, MA) was used to analyze digoxin and prazosin for data collection and integration, including calibration standards. For the analysis of digoxin, an AB Sciex 5500 QTrap mass spectrometer in positive mode $(5500 \mathrm{~V})$ was employed in tandem with a Gemini NX column (at $40^{\circ} \mathrm{C}$; C18, $3 \mu \mathrm{m}, 50 \times 2.0 \mathrm{~mm}$; Phenomenex, Torrance, CA) and a Luna C8 Guard column $(4.0 \times 2.0 \mathrm{~mm})$ for separation in a mobile phase of $0.2 \%$ formic acid in water and $0.2 \%$ formic acid in acetonitrile and an injection volume of $0.5 \mu 1$. The mobile phase flow rate was $0.8 \mathrm{ml} / \mathrm{min}$, and the mass transitions used to identify digoxin were mass to charge ratio $(\mathrm{m} / \mathrm{z})=781.4$ and 651.4. Deuterated digoxin was used as an internal standard and identified with mass transitions of $m / z=784.5$ and 654.5. For the analysis of prazosin, an AB Sciex 5500 QTrap mass spectrometer in positive mode $(3500 \mathrm{~V})$ was employed in tandem with a Waters Atlantis column $\left(\right.$ at $40^{\circ} \mathrm{C}$; $\mathrm{dC} 18,5 \mu \mathrm{m}, 100 \times 2.1 \mathrm{~mm}$; Milford, MA) and a Luna C8 Guard column 
TABLE 2

$\mathrm{IC}_{50}$ values for P450 and UGT inhibition with phosphodiester or phosphorothioate oligonucleotides in HLMs

\begin{tabular}{|c|c|c|c|c|c|c|c|c|c|c|c|c|c|}
\hline \multirow{3}{*}{ Enzyme } & \multirow{3}{*}{ Substrate } & \multicolumn{12}{|c|}{$\mathrm{IC}_{50}$} \\
\hline & & \multicolumn{3}{|c|}{ PD-GP } & \multicolumn{3}{|c|}{ PT-GP } & \multicolumn{3}{|c|}{ PD-Ac } & \multicolumn{3}{|c|}{ PT-Ac } \\
\hline & & Direct & TDI & MDI & Direct & TDI & MDI & Direct & TDI & MDI & Direct & TDI & MDI \\
\hline & & \multicolumn{12}{|c|}{$\mu M$} \\
\hline CYP1A2 & Phenacetin & $>100$ & $>100$ & $>100$ & 0.8 & 0.8 & 1.8 & $>100$ & $>100$ & $>100$ & 4.2 & 3.4 & 7.3 \\
\hline CYP2B6 & Bupropion & $>100$ & $>100$ & $>100$ & 15 & 15 & 13 & $>100$ & $>100$ & $>100$ & 39 & 20 & 22 \\
\hline CYP2C8 & Amodiaquine & $>100$ & $>100$ & $>100$ & 1.1 & 0.6 & 0.6 & $>100$ & $>100$ & $>100$ & 12 & 8.3 & 3.7 \\
\hline CYP2C9 & Diclofenac & $>100$ & $>100$ & $>100$ & 97 & 36 & 47 & $>100$ & $>100$ & $>100$ & $>100$ & 53 & 57 \\
\hline CYP2C19 & $S$-Mephenytoin & $>100$ & $>100$ & $>100$ & 21 & 8.7 & 19 & 29 & 36 & $>100$ & 80 & 39 & 98 \\
\hline CYP2D6 & Dextromethorphan & $>100$ & $>100$ & $>100$ & 81 & 41 & $>100$ & $>100$ & $>100$ & $>100$ & $>100$ & 52 & $>100$ \\
\hline CYP3A4/5 & Midazolam & $>100$ & $>100$ & $>100$ & $>100$ & 38 & 28 & $>100$ & $>100$ & $>100$ & $>100$ & 66 & 63 \\
\hline UGT1A1 & Estradiol & $>100$ & $\mathrm{ND}^{a}$ & ND & 4.5 & ND & ND & $>100$ & ND & ND & 5.4 & ND & ND \\
\hline UGT1A3 & Chenodeoxycholic acid & $>100$ & ND & ND & 51 & ND & ND & $>100$ & ND & ND & 48 & ND & ND \\
\hline UGT1A4 & Trifluoperazine & $>100$ & ND & ND & $>100$ & ND & ND & $>100$ & ND & ND & $>100$ & ND & ND \\
\hline UGT1A6 & 1-Naphthol & $>100$ & ND & ND & 52 & ND & ND & $>100$ & ND & ND & 55 & ND & ND \\
\hline UGT1A9 & Propofol & $>100$ & ND & ND & 19 & ND & ND & $>100$ & ND & ND & 42 & ND & ND \\
\hline UGT2B7 & Morphine & $>100$ & ND & ND & $>100$ & ND & ND & $>100$ & ND & ND & $>100$ & ND & ND \\
\hline UGT2B10 & Levomedetomidine & $>100$ & ND & ND & 26 & ND & ND & $>100$ & ND & ND & 41 & ND & ND \\
\hline UGT2B15 & $S$-Oxazepam & $>100$ & ND & ND & 38 & ND & ND & $>100$ & ND & ND & 45 & ND & ND \\
\hline UGT2B17 & Testosterone & $>100$ & ND & ND & 7.2 & ND & ND & $>100$ & ND & ND & 18 & ND & ND \\
\hline
\end{tabular}

${ }^{a} \mathrm{ND}$ indicates not done. The evaluation of TDI for UGT enzymes was performed at $30 \mu \mathrm{M}$ oligonucleotide only as shown in Supplemental Fig. 2.

$(4.0 \times 2.0 \mathrm{~mm})$ for separation in a mobile phase of $0.2 \%$ formic acid in water and $0.2 \%$ formic acid in acetonitrile and an injection volume of $1 \mu 1$. The mobile phase flow rate was $0.7 \mathrm{ml} / \mathrm{min}$, and the mass transitions used to identify prazosin were $\mathrm{m} / \mathrm{z}=384.0$ and 95.0. Deuterated prazosin was used as an internal standard and was identified with mass transitions of $\mathrm{m} / z=392.0$ and 95.0 .

Statistical Analyses. The means of all replicates were used in all calculations. All $\mathrm{IC}_{50}$ values were determined with GraFit software (version 7.0.2; Erithricus Software Ltd., Surrey, UK). All other data were processed with Microsoft Excel 2010 (Microsoft, Redmond, WA). All of the aforementioned experiments were performed in accordance with Sekisui XenoTech standard operating procedures in the spirit of Good Laboratory Practices.

\section{Results}

Inhibition of P450 and UGT Enzymes by Oligonucleotides in HLMs. To evaluate both phosphodiester- and phosphorothioate-linked oligonucleotides as inhibitors of P450 and UGT enzymes in HLMs, 0.1-100 $\mu \mathrm{M}$ of either PD-GP, PT-GP, PD-Ac or PT-Ac was incubated with HLMs $(\leq 0.1 \mathrm{mg} / \mathrm{ml})$ in the presence or absence of cofactor and with or without a preincubation step as described in the Materials and Methods. As shown in Table 2, the oligonucleotides containing phosphodiester linkages (PD-GP and PD-Ac) had little to no inhibitory effect on any of the P450 and UGT enzymes in HLMs with $\mathrm{IC}_{50}$ values greater than $100 \mu \mathrm{M}$, except for CYP2C19 activity with PD-Ac, which had $\mathrm{IC}_{50}$ values of $29 \mu \mathrm{M}$ with zero preincubation and $36 \mu \mathrm{M}$ after 30-minute preincubation. In contrast, the oligonucleotides containing phosphorothioate linkages (PT-GP and PT-Ac) had broad and varied inhibitory effects on almost all P450 and UGT enzymes evaluated. With respect to P450 enzymes, PT-GP and PT-Ac inhibited CYP1A2 most potently with direct $\mathrm{IC}_{50}$ values of 0.8 and $4.2 \mu \mathrm{M}$, respectively, followed by inhibition of CYP2C8 with direct $\mathrm{IC}_{50}$ values of 1.1 and $12 \mu \mathrm{M}$, respectively (shown in Fig. 2). This inhibition was also found to be dependent on the parent phosphorothioate oligonucleotides and not the result of a low molecular weight chemical impurity or degradation product (see Supplemental Fig. 1). Disruption of the hepatocyte plasma membrane by sonication resulted in restoration of the potent CYP1A2 and CYP2C8 inhibition for both phosphorothioate oligonucleotides (shown in Supplemental Fig. 3). There was evidence of possible TDI by PT-GP and PT-Ac of CYP2B6, CYP2C8, CYP2C19, CYP2C9, CYP2D6, and CYP3A4/5, as indicated by left-shifted $\mathrm{IC}_{50}$ values with preincubation in the absence of NADPH. The TDI for CYP2C8, which had the greatest left-shifted $\mathrm{IC}_{50}$ values, was found to be reversible by ultracentrifugation and reisolation of the microsomal fraction (Fig. 3). For UGT enzymes, PT-GP and PT-Ac inhibited UGT1A1 most potently with direct $\mathrm{IC}_{50}$ values of 4.5 and $5.4 \mu \mathrm{M}$, respectively (as shown in Fig. 2), followed by inhibition of UGT2B17 with direct $\mathrm{IC}_{50}$ values of 7.2 and $18 \mu \mathrm{M}$, respectively. There was no evidence of TDI for UGT enzymes (evaluated at a concentration of $30 \mu \mathrm{M}$ only) as shown in Supplemental Fig. 2. Overall, the rank order of direct inhibition by PT-GP was CYP1A2 $\approx$ CYP2C8 $>$ UGT1A1 > UGT2B17 > $\mathrm{CYP} 2 \mathrm{~B} 6>\mathrm{UGT} 1 \mathrm{~A} 9>\mathrm{CYP} 2 \mathrm{C} 19>\mathrm{UGT} 2 \mathrm{~B} 10>\mathrm{UGT} 2 \mathrm{~B} 15>$ UGT1A $3>$ UGT1A6 $>$ CYP2D6 $>$ CYP2C9, whereas the rank order of direct inhibition by PT-Ac was CYP1A2 $>$ UGT1A1 $>$ CYP2C8 $>$ $\mathrm{UGT} 2 \mathrm{~B} 17>\mathrm{CYP} 2 \mathrm{~B} 6>\mathrm{UGT} 2 \mathrm{~B} 10 \approx \mathrm{UGT} 1 \mathrm{~A} 9 \approx \mathrm{UGT} 2 \mathrm{~B} 15 \approx$ $\mathrm{UGT} 1 \mathrm{~A} 3 \approx \mathrm{UGT} 1 \mathrm{~A} 6>\mathrm{CYP} 2 \mathrm{C} 19$. The $\mathrm{IC}_{50}$ plots of the three most potently inhibited enzymes are shown in Fig. 2.

Inhibition of P450 and UGT Enzymes by Oligonucleotides in CHHs. To determine whether oligonucleotide inhibition of P450 and UGT enzymes was test system dependent, the four oligonucleotides (PD-GP, PT-GP, PD-Ac, and PT-Ac) at $0.1-100 \mu \mathrm{M}$ were evaluated as P450 and UGT inhibitors in CHHs (0.5 million cells $/ \mathrm{ml})$ with and without 30- and 90-minute preincubation as described in the Materials and Methods. In this assay, overall UGT activity based on 4-methylumbelliferone glucuronidation was measured due to the lack of validated specific UGT enzyme substrates in CHHs. As shown in Fig. 4 and Table 3, the phosphodiester-linked oligonucleotides PD-GP and PD-Ac largely had little to no inhibitory effect on P450 and UGT enzymes in CHHs, with the exception of PD-Ac on CYP2C19 activity (direct $\mathrm{IC}_{50}$ of $36 \mu \mathrm{M}$ ). Similarly, the phosphorothioate-linked oligonucleotides PT-GP and PT-Ac had little to no direct inhibitory effect on P450 and UGT enzymes in CHHs ( IC $_{50}$ values $\left.>100 \mu \mathrm{M}\right)$. There was evidence of possible MDI for CYP2C8 and CYP3A4 by PT-GP, as $\mathrm{IC}_{50}$ values decreased at least by a factor of two with increasing preincubation time. However, in the case of CYP3A4, this inhibition was not concentration dependent (curve not shown).

Inhibition of the Uptake Transporters OATP1B1, OATP1B3, OAT1, OAT3, OCT1, and OCT2 and the Efflux Transporters P-gp and BCRP. Both phosphodiester and phosphorothioate variants of the oligonucleotides were tested as inhibitors of uptake transporters in 

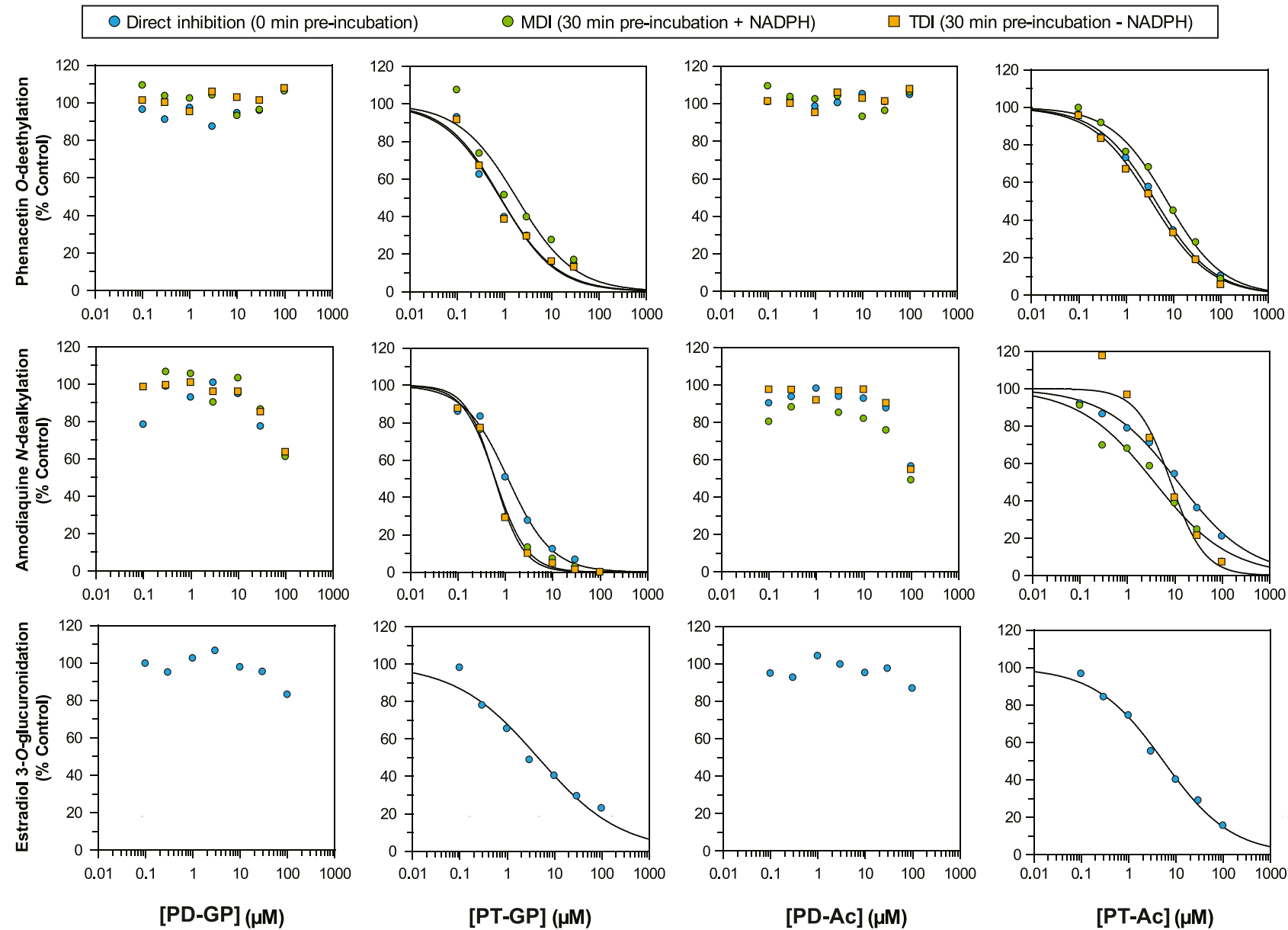

Fig. 2. $\mathrm{IC}_{50}$ plots of CYP1A2, CYP2C8, and UGT1A1 inhibition by phosphodiester- or phosphorothioate-linked oligonucleotides in HLMs. As described in the Materials and Methods, the inhibition of CYP1A2 (phenacetin), CYP2C8 (amodiaquine), and UGT1A1 (estradiol) activity was assessed at 0.1-100 $\mu$ M oligonucleotide in HLMs at $\leq 0.1 \mathrm{mg} / \mathrm{ml}$, with or without a preincubation in the absence of NADPH cofactor (30 minutes) for the evaluation of direct inhibition and TDI, respectively, or in the presence of NADPH cofactor for the evaluation of MDI.

HEK293 cell lines expressing the respective transporters and in Caco-2 or MDCK-II cells expressing efflux transporters as described in the Materials and Methods. As shown in Fig. 5 and Table 4, all four oligonucleotides had little to no inhibitory effect on OATP1B1, OCT1, P-gp or BCRP. For OATP1B3, only PT-GP had significant inhibition with an $\mathrm{IC}_{50}$ of $14 \mu \mathrm{M}$. PD-GP, PT-GP, PD-Ac, and PT-Ac were all inhibitors of OAT1 and OCT2, with $\mathrm{IC}_{50}$ values spanning 12-52 $\mu \mathrm{M}$. PT-GP and PD-Ac were also found to be inhibitors of OAT3, with $\mathrm{IC}_{50}$ values spanning $26-69 \mu \mathrm{M}$.

\section{Discussion}

To date, the publicly available data with oligonucleotide therapeutics, such as eteplirsen, mipomersen, nusinersen, volenesorsen, and defibrotide, have shown no significant pharmacokinetic DDIs with coadministered medicines (Adjei et al., 2003; Villalona-Calero et al., 2004; Geary et al., 2006; Yu et al., 2009; Li et al., 2014; University of Washington DDI database http://www.druginteractioninfo.org), suggesting that, as a class, ASOs do not affect the metabolic pathways of clearance of smallmolecule drugs. This is consistent with the physicochemical properties of ASOs, such as their large molecular weight and polyanionic nature, as well as the assertion that these molecules are not considered prototypical substrates for drug-metabolizing enzymes such as P450s. Furthermore, the proposed mechanism for oligonucleotide uptake into tissues is through endocytosis (Geary et al., 2015; Juliano and Carver, 2015), which would limit the free intracellular oligonucleotide concentration and any potential interactions with drug-metabolizing enzymes located primarily in the hepatic endoplasmic reticulum. With all of this information taken together, it was unexpected to observe in vitro $\mathrm{P} 450$

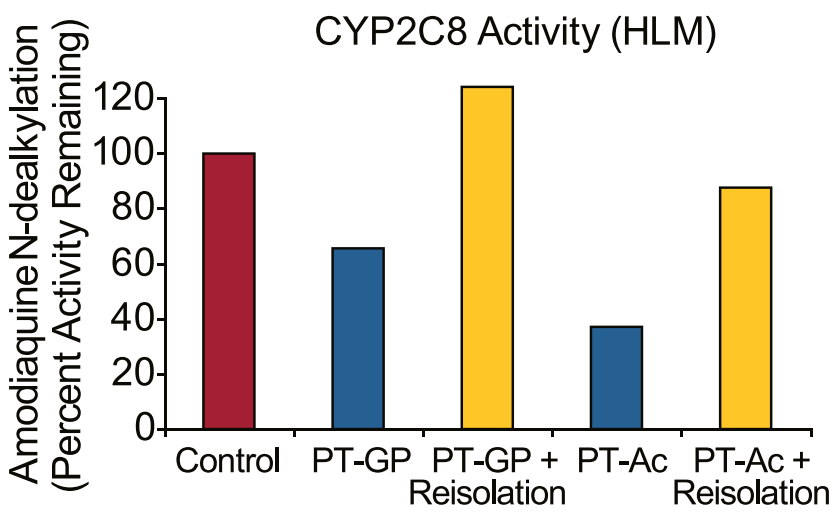

Fig. 3. Assessment of the reversibility of CYP2C8 TDI by phosphorothioate-linked oligonucleotides in HLMs. Phosphorothioate oligonucleotides were incubated at $10 \mu \mathrm{M}$ for 30 minutes in HLMs $(0.0125 \mathrm{mg} / \mathrm{ml})$, followed by ultracentrifugation $(100,000 \mathrm{~g})$ and reisolation of the microsomal fraction as described in the Materials and Methods. Residual CYP2C8 (amodiaquine) activity was assessed after protein normalization. 

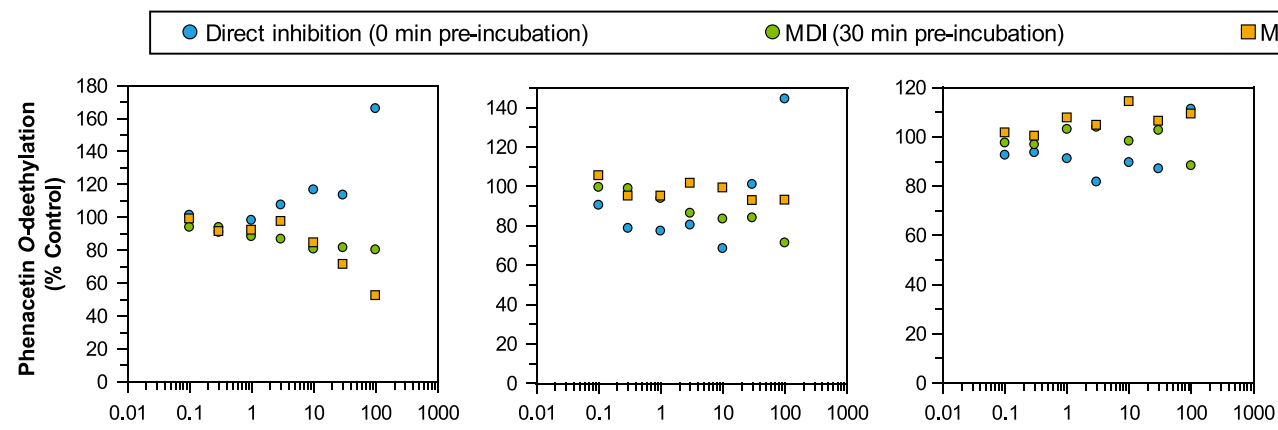

$\square \mathrm{MDI}$ (90 min pre-incubation)

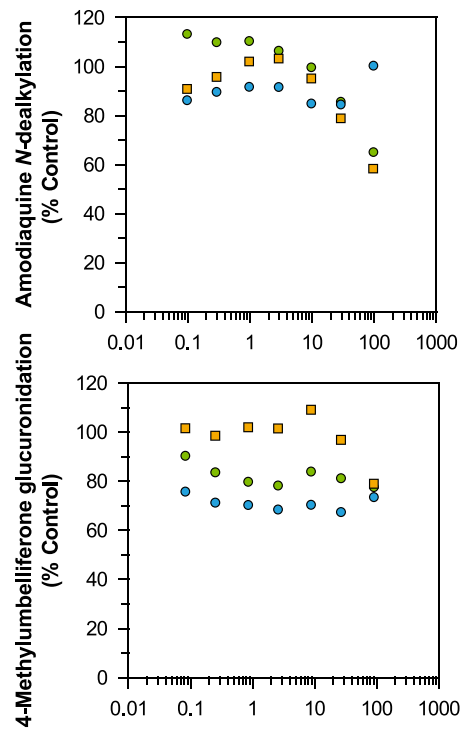

[PD-GP] ( $\mu \mathrm{M})$
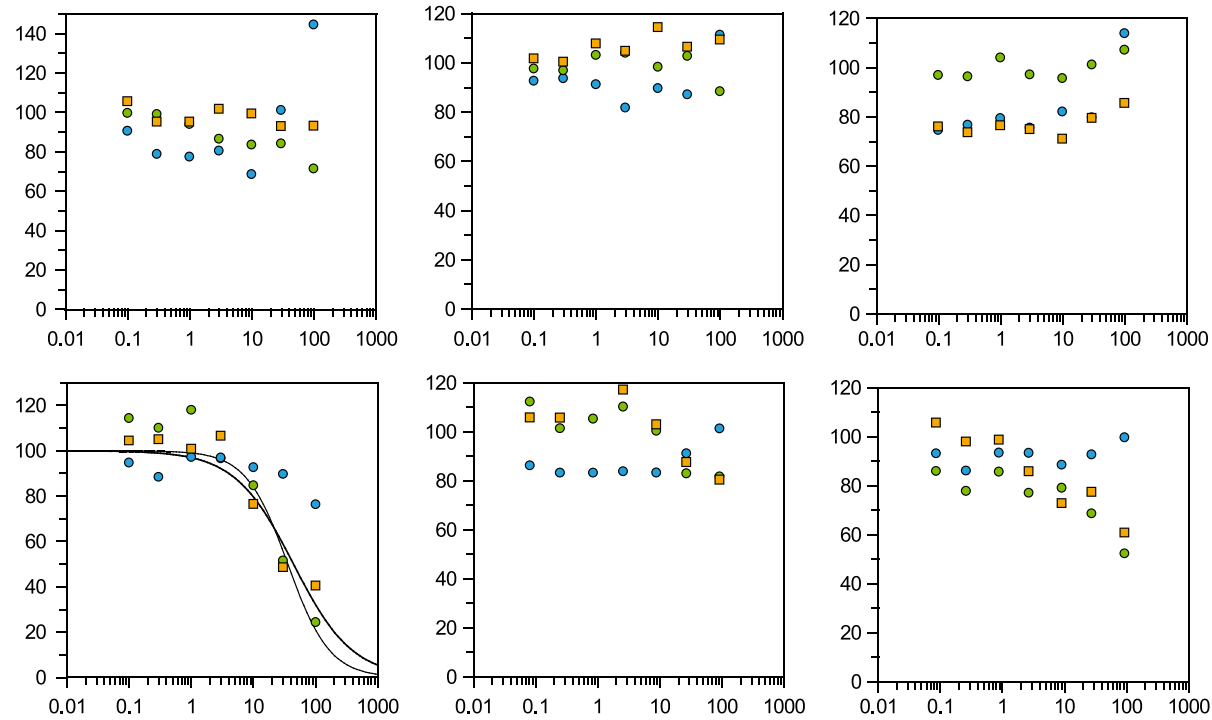

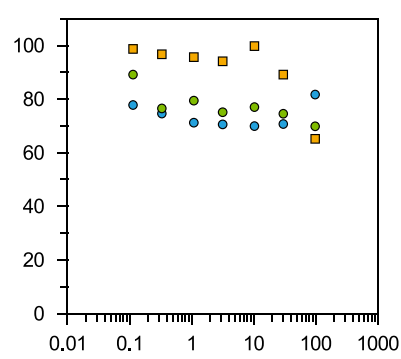

[PT-GP] ( $\mu \mathrm{M})$

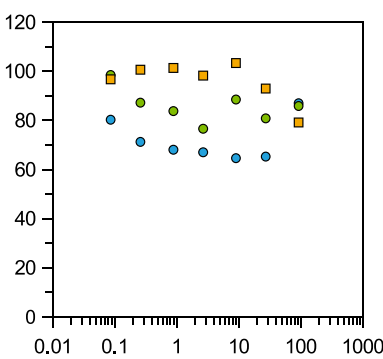

[PD-Ac] $(\mu \mathrm{M})$
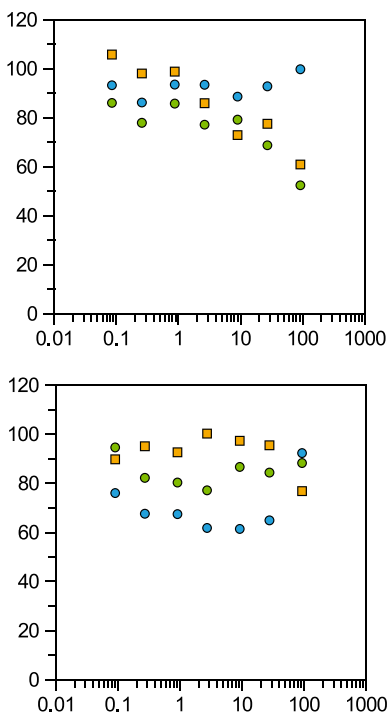

[PT-Ac] $(\mu \mathrm{M})$

Fig. 4. $\mathrm{IC}_{50}$ plots of CYP1A2, CYP2C8, and UGT inhibition by phosphodiester- or phosphorothioate-linked oligonucleotides in CHHs. As described in Materials and Methods, the inhibition of CYP1A2 (phenacetin), CYP2C8 (amodiaquine), and overall UGT (4-methylumbelliferone) activity was assessed at $0.1-100 \mu \mathrm{M}$ oligonucleotide in CHHs at 0.5 million cells/ml, with or without a preincubation (30 and 90 minutes) for the evaluation of direct inhibition and MDI.

inhibition in HLMs by proprietary ASOs in the present study. Considering that phosphodiester oligonucleotides such as mRNA are endogenously present in cells as part of the gene translation process, and are not known to be inhibitors of P450 enzymes, we postulated that the phosphorothioate linkage of these ASOs was contributing to the observed in vitro P450 inhibition.

In this study, we tested this hypothesis by evaluating generic nontherapeutic oligonucleotides (partial sequences to glutathione peroxidase and $\beta$-actin) with either phosphodiester or phosphorothioate linkages (PD-GP and PD-AC or PT-GP and PT-Ac, respectively) as inhibitors of P450, UGT, and select uptake and efflux transporters. As shown in Fig. 2 and Table 2, and consistent with our internal findings with propriety ASOs, the phosphorothioate oligonucleotides evaluated in this study (PT-GP and PT-Ac) inhibited almost all P450 enzymes in HLMs, with potent inhibition of CYP1A2 ( $\mathrm{IC}_{50}$ values of $\left.0.8-4.2 \mu \mathrm{M}\right)$ and $\mathrm{CYP} 2 \mathrm{C} 8\left(\mathrm{IC}_{50}\right.$ values of 1.1-12 $\left.\mu \mathrm{M}\right)$. In addition, almost all UGT

TABLE 3

$\mathrm{IC}_{50}$ values for $\mathrm{P} 450$ and UGT inhibition with phosphodiester or phosphorothioate oligonucleotides in $\mathrm{CHHs}$

\begin{tabular}{|c|c|c|c|c|c|c|c|c|c|c|c|c|c|}
\hline \multirow{3}{*}{ Enzyme } & \multirow{3}{*}{ Substrate } & \multicolumn{12}{|c|}{$\mathrm{IC}_{50}$} \\
\hline & & \multicolumn{3}{|c|}{ PD-GP } & \multicolumn{3}{|c|}{ PT-GP } & \multicolumn{3}{|c|}{ PD-Ac } & \multicolumn{3}{|c|}{ PT-Ac } \\
\hline & & Direct & $\begin{array}{c}\text { MDI } \\
30 \mathrm{~min}\end{array}$ & $\begin{array}{c}\text { MDI } \\
90 \mathrm{~min}\end{array}$ & Direct & $\begin{array}{c}\text { MDI } \\
30 \mathrm{~min}\end{array}$ & $\begin{array}{c}\text { MDI } \\
90 \mathrm{~min}\end{array}$ & Direct & $\begin{array}{c}\text { MDI } \\
30 \mathrm{~min}\end{array}$ & $\begin{array}{c}\text { MDI } \\
90 \mathrm{~min}\end{array}$ & Direct & $\begin{array}{c}\text { MDI } \\
30 \mathrm{~min}\end{array}$ & $\begin{array}{c}\text { MDI } \\
90 \mathrm{~min}\end{array}$ \\
\hline & & \multicolumn{12}{|c|}{$\mu M$} \\
\hline CYP1A2 & Phenacetin & $>100$ & $>100$ & $>100$ & $>100$ & $>100$ & $>100$ & $>100$ & $>100$ & $>100$ & $>100$ & $>100$ & $>100$ \\
\hline CYP2B6 & Bupropion & $>100$ & $>100$ & $>100$ & $>100$ & $>100$ & $>100$ & $>100$ & $>100$ & 77 & $>100$ & $>100$ & $>100$ \\
\hline CYP2C8 & Amodiaquine & $>100$ & $>100$ & $>100$ & $>100$ & 35 & 44 & $>100$ & $>100$ & $>100$ & $>100$ & $>100$ & $>100$ \\
\hline CYP2C9 & Diclofenac & $>100$ & $>100$ & $>100$ & $>100$ & $>100$ & $>100$ & $>100$ & $>100$ & $>100$ & $>100$ & $>100$ & $>100$ \\
\hline CYP2C19 & $S$-Mephenytoin & $>100$ & $>100$ & $>100$ & $>100$ & $>100$ & $>100$ & 36 & $>100$ & $>100$ & $>100$ & $>100$ & $>100$ \\
\hline CYP2D6 & Dextromethorphan & $>100$ & $>100$ & $>100$ & $>100$ & $>100$ & $>100$ & $>100$ & $>100$ & $>100$ & $>100$ & $>100$ & $>100$ \\
\hline CYP3A4/5 & Midazolam & $>100$ & $>100$ & $>100$ & $>100$ & $>100$ & 49 & $>100$ & $>100$ & $>100$ & $>100$ & $>100$ & $>100$ \\
\hline UGT & 4-Methylumbelliferone & $>100$ & $>100$ & $>100$ & $>100$ & $>100$ & $>100$ & $>100$ & $>100$ & $>100$ & $>100$ & $>100$ & $>100$ \\
\hline
\end{tabular}




\section{OATP1B3}

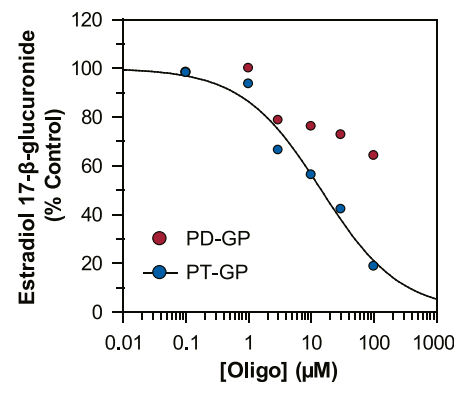

OAT1
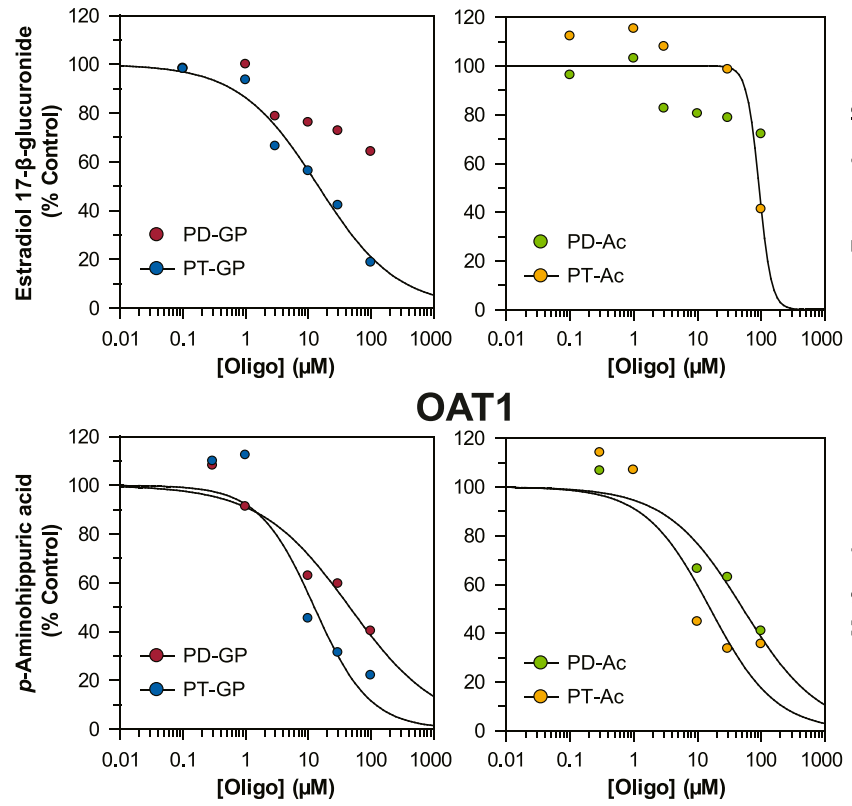

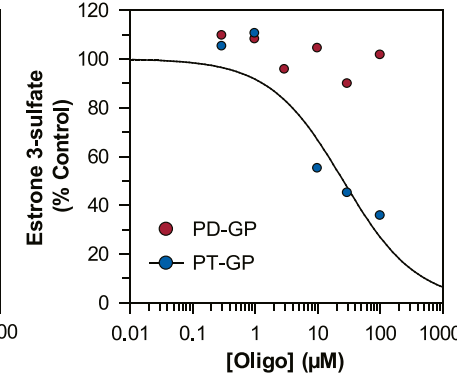

OAT3

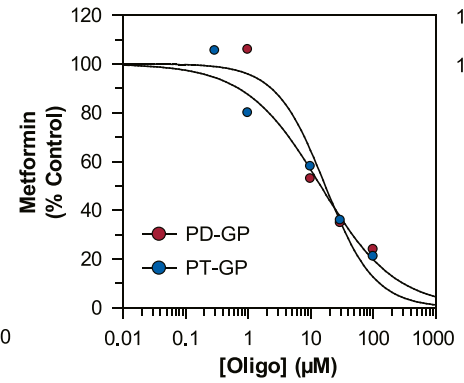

OCT2
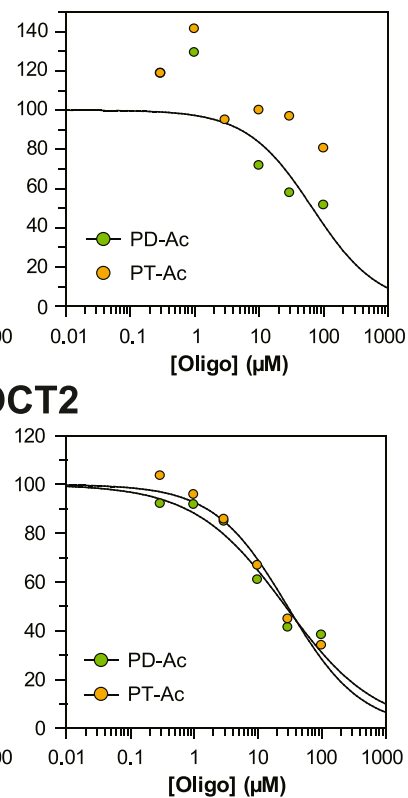

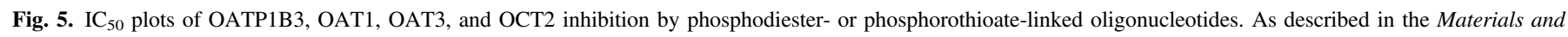

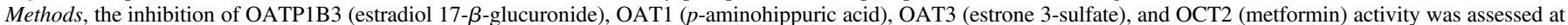
0.1-100 $\mu \mathrm{M}$ oligonucleotide in transporter-overexpressing HEK293 cells.

enzymes were inhibited in HLMs as well, with UGT1A1 inhibited most potently $\left(\mathrm{IC}_{50}\right.$ values of 4.5-5.4 $\left.\mu \mathrm{M}\right)$. In contrast, the phosphodiester oligonucleotides evaluated (PD-GP and PD-Ac) had little to no inhibitory effect on either P450 or UGT enzymes in HLMs, with the exception of CYP2C19 for which moderate direct inhibition was observed. When all four oligonucleotides were evaluated for their ability to inhibit P450 and UGT activity in CHHs, almost all of the inhibition previously observed by the phosphorothioate oligonucleotides in HLMs was attenuated, indicating a clear in vitro test systemdependent inhibitory effect (see Fig. 4; Table 3). Divergent effects on enzyme inhibition with in vitro test systems have been observed previously with some small-molecule drugs (Parkinson et al., 2010). It is possible that test system-dependent inhibitory effects by phosphorothioate oligonucleotides can be attributed to the plasma membrane acting as a permeability barrier, uptake by endocytosis sequestering the oligonucleotides from P450s and UGTs, and enhanced clearance of the oligonucleotides by nucleases in $\mathrm{CHHs}$, all of which would reduce the inhibitory effect in CHHs versus HLMs. This is supported by restored potent inhibition by phosphorothioate oligonucleotides in permeabilized hepatocytes (disruption of the plasma membrane by sonication) to the same extent as HLMs, but not in intact hepatocytes (see Supplemental Fig. 3). However, given their similar structural properties, it is not clear why phosphorothioate oligonucleotides, and not phosphodiester oligonucleotides, caused potent inhibition of CYP1A2, CYP2C8, and UGT1A1 along with moderate inhibition of the other enzymes in HLMs. CYP1A2 typically metabolizes aromatic and heterocyclic amines and prototypical substrates include phenacetin, tacrine, acetanilide, and caffeine (Parkinson et al., 2013). CYP2C8 substrates tend to be large acidic molecules, and substrates include rosiglitazone, repaglinide, amodiaquine, paclitaxel, and several glucuronides (Ogilvie et al., 2006; Kazmi et al., 2015a; Backman et al., 2016). Finally, UGT1A1 is involved in the glucuronidation of many substrates, including etoposide and ezetimibe (Parkinson et al., 2013). Chemically, oligonucleotides are composed of nucleic acid bases coupled to a ribose sugar moiety linked to other nucleotides through a $3^{\prime}$ and $5^{\prime}$ phosphate linkage (see Fig. 1). The structural similarity between purine nucleic acid bases and CYP1A2 prototypical substrates like caffeine may explain the inhibitory finding in HLMs; however, this would suggest that low molecular weight degradation products of the oligonucleotides may be acting as CYP1A2 competitive inhibitors, which is not the case (see Supplemental Fig. 1). Furthermore, oligonucleotides are large polyanionic molecules and share an anionic profile with CYP2C8 and UGT1A1 prototypical substrates (large acidic molecules or glucuronides). Given the anionic substrate preference for these two enzymes, perhaps CYP2C8 and UGT1A1 are more sensitive to oligonucleotide inhibition in HLMs. However, both the purine and anionic interaction scenarios are not exclusive to phosphorothioate oligonucleotides and would be expected to manifest with phosphodiester oligonucleotides as well. It is important to note that the oligonucleotides tested in this study had a low abundance of adenine, and this may have some contribution to enzyme inhibition as well. It is unclear as to the mechanism by which CYP1A2, CYP2C8, and UGT1A1 are the most potently inhibited enzymes in HLMs by phosphorothioate but not phosphodiester oligonucleotides.

TABLE 4

$\mathrm{IC}_{50}$ values for uptake and efflux transporter inhibition with phosphodiester or phosphorothioate oligonucleotides

\begin{tabular}{llcccc}
\hline \multirow{2}{*}{ Transporter } & \multicolumn{4}{c}{ Substrate } & IC $_{50}$ \\
\cline { 3 - 6 } & & PD-GP & PT-GP & PD-Ac & PT-Ac \\
\hline & & \multicolumn{4}{c}{$\mu M$} \\
OATP1B1 & Estradiol 17- $\beta$-glucuronide & $>100$ & 90 & $>100$ & $>100$ \\
OATP1B3 & Estradiol 17- $\beta$-glucuronide & $>100$ & 14 & $>100$ & 92 \\
OAT1 & p-Aminohippuric acid & 46 & 12 & 52 & 16 \\
OAT3 & Estrone 3-sulfate & $>100$ & 26 & 69 & $>100$ \\
OCT1 & Tetraethylammonium bromide & $>100$ & $>100$ & $>100$ & $>100$ \\
OCT2 & Metformin & 17 & 14 & 27 & 29 \\
P-gp & Digoxin & $>100$ & $>100$ & $>100$ & $>100$ \\
BCRP & Prazosin & $>100$ & $>100$ & $>100$ & $>100$ \\
\hline
\end{tabular}


TDI and/or MDI (i.e., preincubation without and with cofactor, respectively) was also observed in HLMs for CYP2B6, CYP2C8, CYP2C19, CYP2C9, CYP2D6, and CYP3A4/5 by the phosphorothioate but not phosphodiester oligonucleotides. In industry practices, two methodologies have been employed to determine $\mathrm{IC}_{50}$ shifts, a comparison between direct and $\mathrm{TDI} \mathrm{IC}_{50}$ curves or a comparison between TDI and MDI IC $_{50}$ curves, with implications for each methodology (Parkinson et al., 2011). A shift in $\mathrm{IC}_{50}$ between direct and $\mathrm{TDI} \mathrm{IC}_{50}$ curves implies that time alone is a factor in more potent inhibition, suggesting that in the case of the phosphorothioate oligonucleotides, a slow on-rate or impaired diffusion due to interactions between the negatively charged microsomal phospholipid bilayer and the polyanionic oligonucleotide molecules is occurring, and not due to $\mathrm{P} 450$ metabolism (MDI $\mathrm{IC}_{50}$ shift). This was examined for CYP2C8 activity by ultracentrifugation and reisolation of the microsomes and the TDI by the phosphorothioate oligonucleotides was shown to be reversible (see Fig. 3), suggesting a slow on-rate inhibitory effect. When we compared TDI and $\mathrm{MDI} \mathrm{IC}_{50}$ curves in HLMs, only PT-Ac inhibition of CYP2C8 had a significant $\mathrm{IC}_{50}$ shift (2.2-fold). In contrast, there was little to no MDI in CHHs by the phosphorothioate oligonucleotides except for CYP2C8 by PT-GP, which is in contrast with the findings in HLMs. An oddity is the direct inhibition of CYP2C19 by PD-Ac in both HLMs and CHHs, which was consistent. It is unclear why this specific phosphodiester-based oligonucleotide caused this effect; however, it may suggest base sequencespecific inhibition of this enzyme.

Oligonucleotide inhibition of select uptake and efflux transporters was also investigated (see Fig. 5; Table 4), and neither phosphorothioate- nor phosphodiester-based oligonucleotides inhibited the uptake transporters OATP1B1 and OCT1 or the efflux transporters P-gp and BCRP. However, inhibition of select uptake transporters, such as OATP1B3, OAT1, OAT3, and OCT2, was observed irrespective of oligonucleotide linkage structure. Inhibition of transporters by oligonucleotides is unusual, as these biomolecules gain cellular entry through endocytosis and not through active uptake mechanisms (Geary et al., 2015; Juliano and Carver, 2015). In addition, recent in vitro studies have shown no significant transporter inhibition for therapeutic phosphorothioate ASOs (Yu et al., 2016; Shemesh et al., 2017). Furthermore, a clinical interaction study with metformin, a drug transported by OCT1, OCT2, and multidrug and toxin extrusion MATE1/MATE2 (Momper et al., 2016), and a therapeutic phosphorothioate ASO (ISIS-113715) reported no clinical DDI (Geary et al., 2006). Given the lack of transporter interactions in literature reports, the inhibition of transporters by the generic oligonucleotides used in this study is through an unknown mechanism and the implications are unclear.

Overall, our findings suggest that phosphorothioate-based oligonucleotide inhibition of P450 and UGT enzymes in HLMs is an in vitro effect without clinical relevance and that $\mathrm{CHH}$ s provide a more clinically relevant inhibitory profile for use in in vitro to in vivo extrapolation of DDIs. This is supported by the lack of clinical interaction reports for ASOs in the literature, which would reconcile with the lack of in vitro $\mathrm{CHH}$ findings by ASOs in this study. Furthermore, a recent in vitro P450 inhibition study with therapeutic phosphorothioate-based ASOs and $\mathrm{CHHs}$ has shown a lack of in vitro inhibition and consequently no predicted in vivo DDI (Shemesh et al., 2017), consistent with the results of this study. As a result, we recommend that for phosphorothioatebased ASOs as a molecule class, P450 and UGT inhibition studies be performed in CHHs and not in HLMs under validated conditions, which include substrate concentrations at approximate $K_{\mathrm{m}}$ with short incubation times to prevent extensive substrate depletion.

\section{Acknowledgments}

We thank Ellis Bixler and the analytical services department at Sekisui XenoTech LLC for technical assistance.

\section{Authorship Contributions}

Participated in research design: Kazmi, Parkinson, Buckley, Ogilvie. Conducted experiments: Yerino, McCoy.

Performed data analysis: Kazmi, Yerino, Buckley.

Wrote or contributed to the writing of the manuscript: Kazmi, Parkinson, Buckley, Ogilvie.

\section{References}

Aartsma-Rus A (2016) New momentum for the field of oligonucleotide therapeutics. Mol Ther 24: 193-194.

Adjei AA, Dy GK, Erlichman C, Reid JM, Sloan JA, Pitot HC, Alberts SR, Goldberg RM, Hanson LJ, Atherton PJ, et al. (2003) A phase I trial of ISIS 2503, an antisense inhibitor of H-ras, in combination with gemcitabine in patients with advanced cancer. Clin Cancer Res 9:115-123.

Backman JT, Filppula AM, Niemi M, and Neuvonen PJ (2016) Role of cytochrome P450 2C8 in drug metabolism and interactions. Pharmacol Rev 68:168-241.

Chen C, Yang Z, and Tang X (2018) Chemical modifications of nucleic acid drugs and their delivery systems for gene-based therapy. Med Res Rev 38:829-869.

Geary RS (2009) Antisense oligonucleotide pharmacokinetics and metabolism. Expert Opin Drug Metab Toxicol 5:381-391.

Geary RS, Bradley JD, Watanabe T, Kwon Y, Wedel M, van Lier JJ, and VanVliet AA (2006) Lack of pharmacokinetic interaction for ISIS 113715 , a 2'-0-methoxyethyl modified antisense oligonucleotide targeting protein tyrosine phosphatase 1B messenger RNA, with oral antidiabetic compounds metformin, glipizide or rosiglitazone. Clin Pharmacokinet 45: 789-801.

Geary RS, Norris D, Yu R, and Bennett CF (2015) Pharmacokinetics, biodistribution and cell uptake of antisense oligonucleotides. Adv Drug Deliv Rev 87:46-51.

Juliano RL and Carver K (2015) Cellular uptake and intracellular trafficking of oligonucleotides. Adv Drug Deliv Rev 87:35-45.

Kazmi F, Barbara JE, Yerino P, and Parkinson A (2015a) A long-standing mystery solved: the formation of 3-hydroxydesloratadine is catalyzed by CYP2C8 but prior glucuronidation of desloratadine by UDP-glucuronosyltransferase $2 \mathrm{~B} 10$ is an obligatory requirement. Drug Metab Dispos 43:523-533.

Kazmi F, Haupt LJ, Horkman JR, Smith BD, Buckley DB, Wachter EA, and Singer JM (2014) In vitro inhibition of human liver cytochrome P450 (CYP) and UDP-glucuronosyltransferase (UGT) enzymes by rose bengal: system-dependent effects on inhibitory potential. Xenobiotica 44:606-614.

Kazmi F, Yerino P, Barbara JE, and Parkinson A (2015b) Further characterization of the metabolism of desloratadine and its cytochrome P450 and UDP-glucuronosyltransferase inhibition potential: identification of desloratadine as a relatively selective UGT2B10 inhibitor. Drug Metab Dispos 43:1294-1302

Li Z, Hard ML, Grundy JS, Singh T, von Moltke LL, and Boltje I (2014) Lack of clinical pharmacodynamic and pharmacokinetic drug-drug interactions between warfarin and the antisense oligonucleotide mipomersen. J Cardiovasc Pharmacol 64:164-171.

Momper JD, Tsunoda SM, and Ma JD (2016) Evaluation of proposed in vivo probe substrates and inhibitors for phenotyping transporter activity in humans. J Clin Pharmacol 56 (Suppl 7): S82-S98.

Ogilvie BW, Yerino P, Kazmi F, Buckley DB, Rostami-Hodjegan A, Paris BL, Toren P, and Parkinson A (2011) The proton pump inhibitor, omeprazole, but not lansoprazole or pantoprazole, is a metabolism-dependent inhibitor of CYP2C19: implications for coadministration with clopidogrel. Drug Metab Dispos 39:2020-2033.

Ogilvie BW, Zhang D, Li W, Rodrigues AD, Gipson AE, Holsapple J, Toren P, and Parkinson A (2006) Glucuronidation converts gemfibrozil to a potent, metabolismdependent inhibitor of CYP2C8: implications for drug-drug interactions. Drug Metab Dispos 34:191-197.

Parkinson A, Kazmi F, Buckley DB, Yerino P, Ogilvie BW, and Paris BL (2010) Systemdependent outcomes during the evaluation of drug candidates as inhibitors of cytochrome P450 (CYP) and uridine diphosphate glucuronosyltransferase (UGT) enzymes: human hepatocytes versus liver microsomes versus recombinant enzymes. Drug Metab Pharmacokinet 25:16-27.

Parkinson A, Kazmi F, Buckley DB, Yerino P, Paris BL, Holsapple J, Toren P, Otradovec SM, and Ogilvie BW (2011) An evaluation of the dilution method for identifying metabolismdependent inhibitors of cytochrome P450 enzymes. Drug Metab Dispos 39:1370-1387.

Parkinson A, Mudra DR, Johnson C, Dwyer A, and Carroll KM (2004) The effects of gender, age, ethnicity, and liver cirrhosis on cytochrome P450 enzyme activity in human liver microsomes and inducibility in cultured human hepatocytes. Toxicol Appl Pharmacol 199: 193-209.

Parkinson A, Ogilvie BW, Buckley DB, Kazmi F, Czerwinski M, and Parkinson O (2013) Biotransformation of xenobiotics, in Casarett \& Doull's Toxicology: The Basic Science of Poisons (Klaassen CD ed) pp 185-367, McGraw-Hill Inc., New York.

Pearce RE, Rodrigues AD, Goldstein JA, and Parkinson A (1996) Identification of the human P450 enzymes involved in lansoprazole metabolism. J Pharmacol Exp Ther 277:805-816.

Rossor AM, Reilly MM, and Sleigh JN (2018) Antisense oligonucleotides and other genetic therapies made simple. Pract Neurol 18:126-131.

Shemesh CS, Yu RZ, Warren MS, Liu M, Jahic M, Nichols B, Post N, Lin S, Norris DA, Hurh E, et al. (2017) Assessment of the drug interaction potential of unconjugated and $\mathrm{GalNAc}_{3}$-conjugated 2'-MOE-ASOs. Mol Ther Nucleic Acids 9:34-47.

Vasko T, Kaifie A, Stope MB, Kraus T, and Ziegler P (2017) Telomeres and telomerase in hematopoietic dysfunction: prognostic implications and pharmacological interventions. Int J Mol Sci 18:E2267. 
Vermeer LM, Isringhausen CD, Ogilvie BW, and Buckley DB (2016) Evaluation of ketoconazole and its alternative clinical CYP3A4/5 inhibitors as inhibitors of drug transporters: the in vitro effects of ketoconazole, ritonavir, clarithromycin, and itraconazole on 13 clinically-relevant drug transporters. Drug Metab Dispos 44:453-459.

Villalona-Calero MA, Ritch P, Figueroa JA, Otterson GA, Belt R, Dow E, George S, Leonardo J, McCachren S, Miller GL, et al. (2004) A phase I/II study of LY900003, an antisense inhibitor of protein kinase $\mathrm{C}$-alpha, in combination with cisplatin and gemcitabine in patients with advanced non-small cell lung cancer. Clin Cancer Res 10:6086-6093.

Yu RZ, Geary RS, Flaim JD, Riley GC, Tribble DL, vanVliet AA, and Wedel MK (2009) Lack of pharmacokinetic interaction of mipomersen sodium (ISIS 301012), a 2'-O-methoxyethyl modified antisense oligonucleotide targeting apolipoprotein B-100 messenger RNA, with simvastatin and ezetimibe. Clin Pharmacokinet 48:39-50.
Yu RZ, Grundy JS, and Geary RS (2013) Clinical pharmacokinetics of second generation antisense oligonucleotides. Expert Opin Drug Metab Toxicol 9:169-182.

Yu RZ, Warren MS, Watanabe T, Nichols B, Jahic M, Huang J, Burkey J, Geary RS, Henry SP, and Wang Y (2016) Lack of interactions between an antisense oligonucleotide with 2 '-O-(2-methoxyethyl) modifications and major drug transporters. Nucleic Acid Ther 26: 111-117.

Address correspondence to: Dr. Faraz Kazmi, Janssen Research and Development, 1400 McKean Road, Spring House, PA 19477. E-mail: fkazmi@its.jnj.com 